\title{
Testicular Nitric Oxide and Thiobarbituric Acid Reactive Substances Levels in Obstructive Azoospermia: A Possible Role in Pathophysiology of Infertility
}

\author{
M. Murad Başar, ${ }^{1}$ Üçler Kisa, ${ }^{2}$ Devrim Tuğlu, ${ }^{1}$ Erdal Yilmaz, ${ }^{1}$ Halil Başar, ${ }^{1}$ \\ Osman Çağlayan, ${ }^{2}$ and Ertan Batislam ${ }^{1}$ \\ ${ }^{1}$ Department of Urology, Faculty of Medicine, University of Kırıkkale, 71100 Kırıkkale, Turkey \\ ${ }^{2}$ Department of Clinical Biochemistry, Faculty of Medicine, University of Kırıkale, 71100 Kırıkale, Turkey
}

Received 27 October 2005; Revised 2 January 2006; Accepted 23 January 2006

Objective. The aim of the study is to evaluate the levels of nitrite/nitrate and thiobarbituric acid reactive substances (TBARS) and their relationship with seminal parameters in experimental obstructive azoospermic rats to explain the possible mechanism of impaired sperm quality in obstructive azoospermia. Methods. A total of 10 male Spraque-Dawley rats underwent bilateral vas resection and ligation (Group-1 = vasectomy group). The findings were compared with control group (Group-2 = sham group, $n=10$ ). Animals were sacrificed 8 weeks after surgery. Testes were removed and used for the evaluation of nitrate/nitrite and TBARS levels and for histology. Epididymal-aspirated seminal plasma was used for semen count and morphological analysis according to the Kruger criteria. Results. Testicular tissue nitrate/nitrite and TBARS levels were $35.7 \pm 3.1 \mu \mathrm{mol} / \mathrm{g}$ protein and $3.7 \pm 0.1 \mathrm{nmol} / \mathrm{g}$ protein in Group-1, and $19.3 \pm 0.7 \mu \mathrm{mol} / \mathrm{g}$ protein and $3.1 \pm 0.1 \mathrm{nmol} / \mathrm{g}$ protein in Group-2, respectively. Both parameters showed statistical differences between the two groups. Testicular tissue nitrate/nitrite and TBARS levels showed negative and statistically significant correlations with sperm motility and morphology. Conclusions. The present study showed that testicular nitrate/nitrite and TBARS levels were increased in obstructive azoospermia. For that reason, we concluded that antioxidant treatment can be recommended to patients before sperm extraction for artificial reproduction due to obstructive infertility after vasectomy reversal.

Copyright (c) 2006 M. Murad Başar et al. This is an open access article distributed under the Creative Commons Attribution License, which permits unrestricted use, distribution, and reproduction in any medium, provided the original work is properly cited.

\section{INTRODUCTION}

Obstructive azoospermia is due to congenital and acquired causes. Although microsurgical techniques are performed in the treatment, the success rates are very low. In the literature while patency rate after surgery has been reported around 80-90\%, pregnancy rate and living birth rates have still been less than $50 \%$ [1-3]. Recently, fertilization is possible by using epididymal or testicular spermatozoa with developments of sperm retrieval techniques and intracytoplasmic sperm injection. Although there are no hormonal or testicular failures in these patients, the sperm quality has usually been poor. While sperm concentration is generally normal in these patients, asthenozoospermia and teratozoospermia can be observed after epididymal or testicular sperm aspiration [4-6].

Human spermatozoa are rich in polyunsaturated fatty acids, and therefore are susceptible to reactive oxygen substance (ROS) attack and thiobarbituric acid reactive sub- stances (TBARS) indicated lipid peroxidation $[7,8]$. In obstructive azoospermia patients, these substances were increased in several studies [7]. The mechanism of infertility in these males is direct generation of oxygen radicals by leucocytes, sperm damage as a result of epididymal obstruction, and presence of immature sperm as a result of testicular damage due to prior obstruction $[9,10]$.

In a previous study of infertile cases, it was shown that increased lipid peroxidation was related to seminal plasma nitric oxide (NO) levels [11]. Therefore, while increased lipid peroxidation causes cytotoxic effects, increased NO causes impaired sperm motility. However, the relationship of these molecules with sperm parameters has not been investigated yet.

The aims of this study are to evaluate the levels of TBARS as an indication of lipid peroxidation and nitrate/nitrite levels in testicular tissue, and to evaluate the relationship between these molecules and sperm concentration, motility, 
and morphology. Therefore, we tried to explain the possible mechanism of impaired sperm quality in obstructive azoospermic patients.

\section{MATERIALS AND METHODS}

Twenty adult male Sprague-Dawley rats which weighed between 205-220 g were enrolled into the study. All rats were allowed free access, a standard rat laboratory diet, and tap water. The study was started after taking permission from Local Ethical Authority. Unnecessary suffering was avoided during the study, and all procedures were performed under anaesthesia.

Rats were divided into two groups randomly. A total of 10 male Sprague-Dawley rats (mean weight $212.2 \pm 8.9 \mathrm{~g}$; mean age $8.8 \pm 0.6$ weeks) in Group-1 (vasectomy group) were assigned to the study group, and they were operated under $2 \mathrm{cc}$ intraperitoneal ketamine hydrochloride 5\% anaesthesia. Pfannenstiel incision was performed and both testes removed from this incision. Epididymis and vas deference were identified in both sides. Subsequently, total vasectomy and vasal excision around $1 \mathrm{~cm}$ were performed at the vasoepididymal junction in both sides. After placing testes, the incision was closed with 3-zero silk sutures. Sham operation was performed on another 10 rats (mean weight $210.6 \pm 8.3 \mathrm{~g}$; mean age $8.4 \pm 0.5$ weeks) (Group- $2=$ sham group). Vas deference was only explorated under 2 cc intraperitoneal ketamine hydrochloride $5 \%$ anaesthesia by using same incision mentioned above.

Animals were sacrificed 8 weeks after surgery with high-dose ketamine hydrochloride anaesthesia $(10 \mathrm{mg} / \mathrm{kg})$. Testes were removed and half of each testis was fixed in Bouin's solution and embedded in parafilm. Histological sections were stained with haematoxylin and eosin, and observed by light microscopy.

The rest of testicular tissues was frozen by liquid nitrogen and stored at $-80^{\circ} \mathrm{C}$ until investigation. After washing with $0.9 \% \mathrm{NaCl}$, tissues were homogenized in ice with $1 \mathrm{~mL}$ $0.9 \% \mathrm{NaCl}$ solution (Labor Technique, Germany). Homogenized tissues were centrifuged at $1500 \mathrm{xg}$ for 10 minutes at $4^{\circ} \mathrm{C}$. Supernatants were used for protein, nitrate/nitrite levels, and TBARS determination. Protein level was measured using Lowry's method [12]. TBARS levels indicated of lipid peroxidation were measured as described by Armstrong and al-Awadi, who modified the Yagi method [13]. The calibration curve was prepared with 1, 1,3,3-tetramethoxypropane (Sigma, USA) standards of $1-25 \mathrm{nM}$ dilutions. The results were calculated as $\mathrm{nmol} / \mathrm{g}$ protein.

Nitrite/nitrate levels were measured as described by Miranda et al [14]. Nitrate was reduced to nitrite with vanadium (III) and then nitrite level measured by using Griess reagents. This reflects the total amount of nitrate and nitrite in the sample. Serial dilutions $0.5-250 \mu \mathrm{M}$ of $\mathrm{Na}$ nitrate (Merck, Germany) were used as standards and the results were expressed as $\mu \mathrm{mol} / \mathrm{g}$ protein.

Seminal plasma aspirated from the caudal part of the left epididymis in all rats was used for semen analysis. Epididymal content aspirated with insulin syringe contained $1 \mathrm{~mL}$ sperm wash medium (Irvine Scientific, Calif, USA). Later, this sperm was transferred into a $1.5 \mathrm{~mL}$ Falcon tube. After mixing with Pasteur pipette, $5 \mu \mathrm{L}$ of the solution was put on Makler chamber for the evaluation of sperm count and motility with light microscope under $\times 40$ magnification. Morphological analysis was performed after staining Sperm Mac (Ferti Net NV, Belgium) stain of slide. The slide preparations were fixed for 5 minutes; later, all samples were stained in three different stain solutions for 1 minute in each solution. All preparations were examined for morphology at a magnification of $\times 100$ using immersion oil. One hundred spermatozoa were evaluated for determination of the sperm morphology ratio in each preparation according to the strict criteria of Kruger [15]. The criteria for a normal sperm head are as follows: head length is 4 to $6 \mu \mathrm{m}$, width is 2.5 to $3.5 \mu \mathrm{m}$, acrosomal size is $40 \%$ to $70 \%$ of total sperm head, area midpiece is less than $1 \mu$ width and 1.5 fold of the head length, tail is uniform, thinner than midpiece, uncoiled, free from kings, and approximately $45 \mu$ long. Since there has not been any report about normal rat semen parameters, our control group's results were accepted as normal.

Statistical analysis was performed by using MannWhitney $U$ and Spearman correlation tests between two groups and nitrate/nitrite and TBARS levels and seminal parameters. Statistical significance was accepted if $P$ value was less than .05 .

\section{RESULTS}

Testicular tissue nitrate/nitrite and TBARS levels and seminal plasma parameters are shown in Table 1. Testicular tissue nitrate/nitrite and TBARS levels showed statistically significant differences between two groups $\left(P_{\text {nitrate/nitrite }}=.000\right.$, $P_{\text {TBARS }}=.000$ ).

The results of semen analysis are given in Table 1. There were differences in sperm motility, morphology, and the agglutinated sperm ratio between both two groups $\left(P_{\text {motility }}=\right.$ $\left..000, P_{\text {morphology }}=.000, P_{\text {agglutination }}=.000\right)$. On the contrary, no differences were observed in sperm concentration and seminal leukocyte counts were less than 1 million per millilitre in both groups. With respect to morphology, head abnormalities were observed in $58.8 \pm 0.4 \%$ of the spermatozoa, midpiece and neck $15.3 \pm 0.4 \%$, and tail $22.2 \pm 0.4 \%$ in Group-1. These abnormalities were observed in Group2 as $57.1 \pm 0.3 \%, 14.7 \pm 0.3 \%$, and $20.3 \pm 0.3 \%$, respectively. Statistically significant differences were observed between head and tail abnormalities agglutinated sperm ratio $\left(P_{\text {head }}=.011, P_{\text {tail }}=.005\right)$.

Testicular tissue nitrate/nitrite and TBARS levels showed statistically significant negative correlations with sperm motility and morphology (for nitrate/nitrite: $r_{\text {motility }}=$ $-0.722, P_{\text {motility }}=.000 ; r_{\text {morphology }}=-0.633, P_{\text {morphology }}=$ .003 ; for TBARS: $r_{\text {motility }}=-0.745, P_{\text {motility }}=.000$; $\left.r_{\text {morphology }}=-0.541, P_{\text {morphology }}=.003\right)($ Figures 1 and 2$)$.

In histopathologic examination of the testis, there was not any difference between both groups. Seminiferous tubules, germinal cells, Sertoli, and Leydig cells were in normal appearance. Basement membrane of seminiferous 
TABLE 1: Testicular tissue nitrate/nitrite and TBARS levels and semen analysis results in study (Group-1) and control (Group-2) groups $($ Mean \pm SEM).

\begin{tabular}{l|rr}
\hline & Group-1 & Group-2 \\
\hline Nitrate/nitrite $(\mu \mathrm{mol} /$ g protein) & $35.6 \pm 3.1^{* *}$ & $19.3 \pm 0.7$ \\
TBARS (nmol/g protein) & $3.7 \pm 0.1^{* *}$ & $3.1 \pm 0.1$ \\
Spermatozoa concentration $\left(10^{6} / \mathrm{mL}\right)$ & $2.4 \pm 0.1$ & $2.7 \pm 0.1$ \\
Motility (\%) & $39.4 \pm 0.9^{* *}$ & $64.9 \pm 0.8$ \\
Morphology (\% of normal spermatozoa) & $4.3 \pm 0.2^{* *}$ & $5.9 \pm 0.2$ \\
Head abnormality (\%) & $58.8 \pm 0.4^{*}$ & $57.1 \pm 0.3$ \\
Midpiece and neck abnormality (\%) & $15.3 \pm 0.4$ & $14.7 \pm 0.3$ \\
Tail abnormality (\%) & $22.2 \pm 0.4^{* *}$ & $20.3 \pm 0.3$ \\
Agglutination $(\%)$ & $0.8 \pm 0.02^{* *}$ & $0.6 \pm 0.02$ \\
\hline
\end{tabular}

* Significantly different from control $(P=.05) ; * *(P=.001)$.

tubules was normal, and all stages of sperm cells were found in seminiferous tubules.

\section{DISCUSSION}

Although the sperm concentration is generally sufficient for fertilization, the reasons for the impaired sperm quality in patients with obstructive azoospermia have not been understood. Moreover, impaired sperm quality and low pregnancy rates have also been found after vasectomy reversal. For that reason, some additional factors can be causes of these conditions. Epididymal dysfunction and antisperm antibody (ASA) are possible contributing factors $[5,8,16]$.

It is known that lipid peroxidation substances called ROS or TBARS and total antioxidant capacity (TAC) can be found in human ejaculate physiologically. While these substances show some effects on normal sperm function, increased levels may cause harmful effects such as capacitation and acrosome reaction defects $[8,16]$. Increased lipid peroxidation substance levels have been shown in obstructive infertile patients, especially after vasectomy reversal in some studies [9, 10]. In these men, oxidative stress substances were negatively related to sperm concentration and morphology, whereas TAC was positively related to morphology. Postulated mechanisms for the infertility among these patients are direct generation of oxygen radicals by leucocytes, sperm damage as a result of epididymal blockage, alterations within the immune mechanism, and the presence of immature sperm as a result of testicular damage $[9,10]$. It was reported that seminal plasma ROS and TAC levels did not differ between fertile and infertile groups [9], but significant differences in ROS existed between vasectomy reversal patients and normal donors. So, the authors concluded that there was a possible relationship between oxidative stress and vasectomy reversal, but not between oxidative stress and fertility. However, there are a few reports on oxidative stress in obstructive azoospermic patients. Some authors investigated testicular tissue ROS levels in unilateral vasectomized rats and found that increased ROS levels in ipsilateral testicular tissue were related to histological damages [17]. Moreover, they concluded that some immunohistochemical changes such as abundant collagen fibril accumulation in the peritubular area, intense IgG antibodies in testis, and intense antivimentin antibodies in peritubular myoid cells were observed in both testes [18]. However, in the present study, in spite of the increased TBARS levels, we did not observe gross morphological changes in both testes after vasal ligation. On the other hand, it was reported that superoxide radical was increased in the granuloma side after vasectomy [19]. However, we aimed in the present study to investigate the levels of nitrate/nitrite and TBARS in only testicular tissue after performing bilateral vasectomy.

In human, $\mathrm{NO}$ is an important messenger in several tissues, including the reproductive system. In male and female, different cell types such as endothelial cells, smooth muscle cells, fibroblasts, and phagocytes are capable of NO release $[20,21]$. The effects of NO in seminal plasma changed with its plasma concentration. In physiologic concentration, NO acts a role as a mediator of the aforementioned tissues and cells. On the contrary, the harmful effects of NO are mediated by biologically activate molecules produced by the reaction of NO with the oxidant molecules $[11,22]$. In the literature, there is some knowledge about the correlation of seminal plasma $\mathrm{NO}$ concentration and sperm quality in infertile patients with varicocele $[22,23]$. Decreased semen concentration caused by increased $\mathrm{NO}$ was due to direct inhibition of mitochondrial respiration and DNA synthesis. NO can reduce ATP levels in cells. Therefore, decreased ATP content or production might result in insufficient energy and poor sperm motility because approximately $90 \%$ of the energy is produced as ATP $[24,25]$. However, the seminal plasma NO concentration has not been investigated in the obstructive azoospermia population.

In the present study, we found that testicular tissue nitrate/nitrite, as an index of NO production, and TBARS levels were elevated in rats with vaso-epididymal obstruction. Moreover, when increased levels of these substances were compared to seminal parameters, there were negative and significant correlations between testicular tissue nitrate/nitrite and TBARS levels and sperm motility and morphology in vasectomy group.

Recently, antioxidant treatment with carnitine, callicreine, vitamins $\mathrm{A}, \mathrm{E}$, and $\mathrm{C}$ has been recommended to infertile patients over the years $[26,27]$. Moreover, antioxidants have been used in patients who underwent testicular sperm 


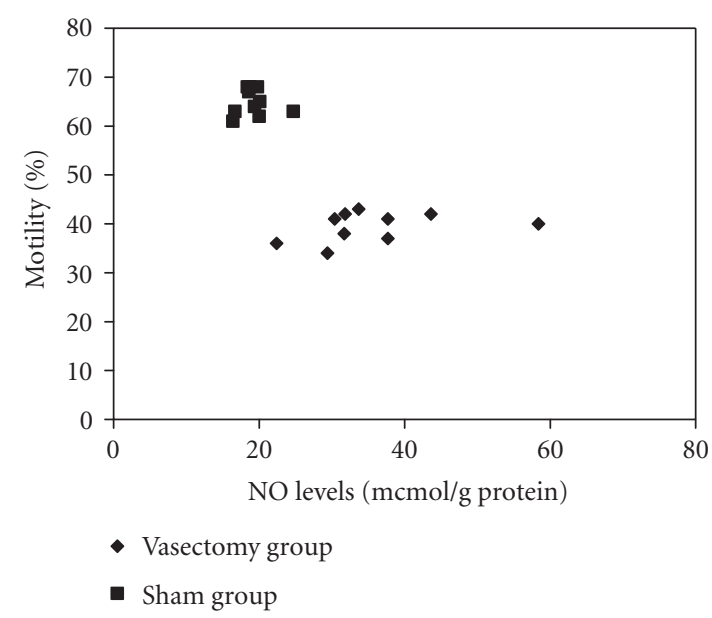

(a)

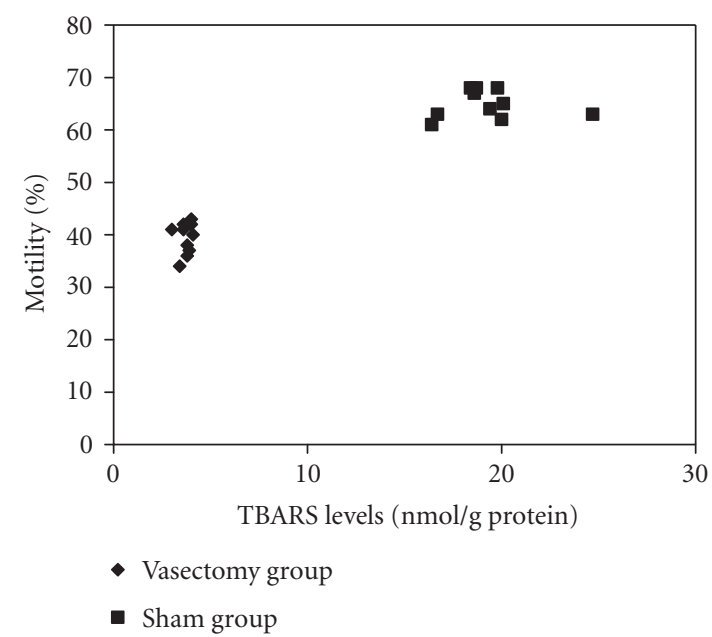

(b)

FIGURE 1: Correlation between sperm motility and seminal plasma NO (a) and TBARS (b) levels in both groups.

extraction for intracytoplasmic sperm injection (ICSI) and in patients having testicular tortion for prophylaxis [28-30]. However, the effects of these therapies are controversial.

In conclusion, we thought that increased testicular nitrate/nitrite and TBARS levels indicative of lipid peroxidation levels showed oxidative stress in obstructive azoospermia. This condition can be one of the causes of decreased sperm quality in these cases. Although the present study is done in experimental settings, we thought that antioxidant treatment might be recommended to the obstructive infertility patients before sperm extraction for ICSI. However, our study was designed for laboratory animals and these results should be confirmed in human studies.

\section{REFERENCES}

[1] Sigman M. The relationship between intravasal sperm quality and patency rates after vasovasostomy. The Journal of Urology. 2004;171(1):307-309.

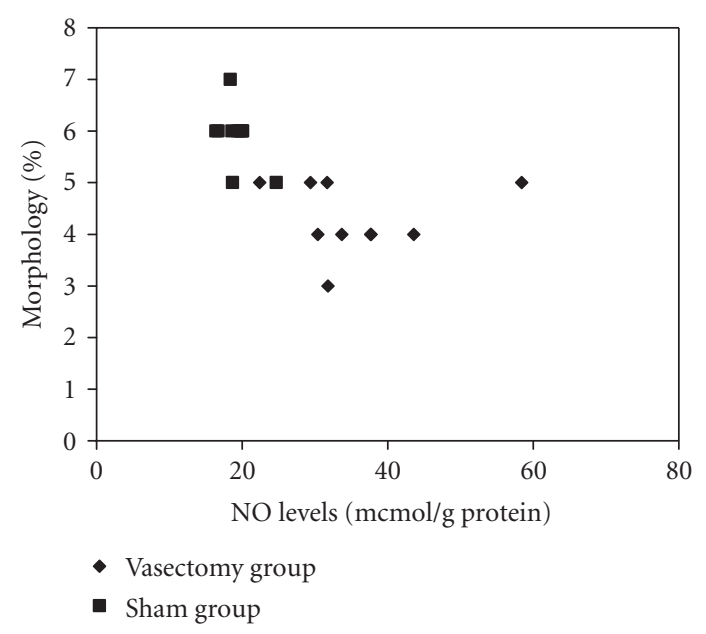

(a)

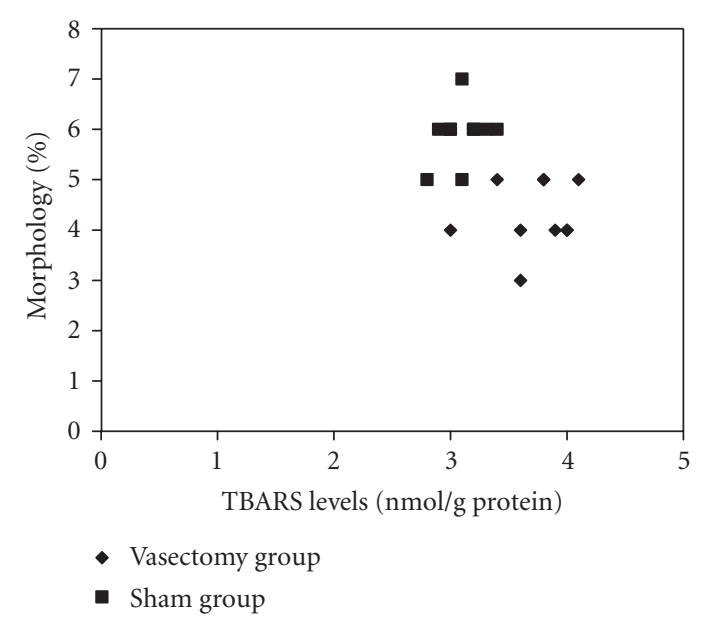

(b)

Figure 2: Correlation between sperm morphology and seminal plasma NO (a) and TBARS (b) levels in both groups.

[2] Kolettis PN, Sabanegh ES, Nalesnik JG, D'Amico AM, Box LC, Burns JR. Pregnancy outcomes after vasectomy reversal for female partners 35 years old or older. The Journal of Urology. 2003;169(6):2250-2252.

[3] Paick JS, Park JY, Park DW, Park K, Son H, Kim SW. Microsurgical vasovasostomy after failed vasovasostomy. The Journal of Urology. 2003;169(3):1052-1055.

[4] Sigman M, Jarow JP. Male infertility. In: Walsh PC, Retik AB, Vaughan ED Jr, Wein AJ, eds. Campbell's Urology. Philadelphia, Pa: Saunders; 2002:1475-1531.

[5] Schoysman R. Microsurgery of Male Infertility. Brussels, Belgium: Fondazione Per Gli Studi Sulla Riproduzione Umana; 1994.

[6] Sigman M. Assisted reproductive techniques and male infertility. The Urologic Clinics of North America. 1994;21(3):505-515.

[7] Sharma RK, Agarwal A. Role of reactive oxygen species in male infertility. Urology. 1996;48(6):835-850.

[8] Pasqualotto FF, Sharma RK, Nelson DR, Thomas AJ Jr, Agarwal A. Relationship between oxidative stress, semen characteristics, and clinical diagnosis in men undergoing infertility investigation. Fertility and Sterility. 2000;73(3):459-464. 
[9] Kolettis PN, Sharma RK, Pasqualotto FF, Nelson D, Thomas AJ Jr, Agarwal A. Effect of seminal oxidative stress on fertility after vasectomy reversal. Fertility and Sterility. 1999;71(2):249-255.

[10] Shapiro RH, Muller CH, Chen G, Berger RE. Vasectomy reversal associated with increased reactive oxygen species production by seminal fluid leukocytes and sperm. The Journal of Urology. 1998;160(4):1341-1346.

[11] Romeo C, Ientile R, Impellizzeri P, et al. Preliminary report on nitric oxide-mediated oxidative damage in adolescent varicocele. Human Reproduction. 2003;18(1):26-29.

[12] Lowry OH, Rosebrough NJ, Farr AL, Randall RJ. Protein measurement with the Folin phenol reagent. The Journal of Biological Chemistry. 1951;193(1):265-275.

[13] Armstrong D, al-Awadi F. Lipid peroxidation and retinopathy in streptozotocin-induced diabetes. Free Radical Biology \& Medicine. 1991;11(4):433-436.

[14] Miranda KM, Espey MG, Wink DA. A rapid, simple spectrophotometric method for simultaneous detection of nitrate and nitrite. Nitric Oxide. 2001;5(1):62-71.

[15] Kruger TF, Du Toit TC, Franken DR, et al. A new computerized method of reading sperm morphology (strict criteria) is as efficient as technician reading. Fertility and Sterility. 1993;59(1):202-209.

[16] de Lamirande E, Gagnon C. Impact of reactive oxygen species on spermatozoa: a balancing act between beneficial and detrimental effects. Human Reproduction. 1995;10(suppl 1):15-21.

[17] Aydos K, Küpeli B, Soygür T, et al. Analysis of the relationship between histologic alterations and generation of reactive oxygen species in vasectomized rat testes. Urology. 1998;51(3): 510-515.

[18] Aydos K, Soygür T, Küpeli B, et al. Testicular effects of vasectomy in rats: an ultrastructural and immunohistochemical study. Urology. 1998;15(6):1051-1056.

[19] Chatterjee S, Rahman MM, Lalorya M, Kumar GP. Sperm disposal system in spermatic granuloma: a link with superoxide radicals. International Journal of Andrology. 2001;24(5):278283.

[20] Knowles RG, Moncada S. Nitric oxide synthases in mammals (review). The Biochemical Journal. 1994;298(pt 2):249-258.

[21] Nathan C. Nitric oxide as a secretory product of mammalian cells. The FASEB Journal. 1992;6(12):3051-3064.

[22] Ozbek E, Turkoz Y, Gokdeniz R, Davarci M, Ozugurlu F. Increased nitric oxide production in the spermatic vein of patients with varicocele. European Urology. 2000;37(2):172-175.

[23] Aksoy Y, Ozbey I, Aksoy H, Polat Ö, Akcay F. Seminal plasma nitric oxide concentration in oligo- and/or asthenozoospermic subjects with/without varicocele. Archives of Andrology. 2002;48(3):181-185.

[24] Weinberg JB, Doty E, Bonaventure J, Haney AF. Nitric oxide inhibition of human sperm motility. Fertility and Sterility. 1995;64(2):408-413.

[25] Hibbs JB Jr, Traintor RR, Vavrin Z, et al. Synthesis of nitric oxide from a terminal guanidine nitrogen atom of L-Arginine: a molecular mechanism regulating cellular proliferation that targets intracellular iron. In: Moncada S, Higgs EA, eds. Nitric Oxide From L-Arginine: A Bioregulatory System. Amsterdam, Holland: Elsevier; 1990:189-223.

[26] Lenzi A, Gandini L, Picardo M, Tramer F, Sandri G, Panfili E. Lipoperoxidation damage of spermatozoa polyunsaturated fatty acids (PUFA): scavenger mechanisms and possible scavenger therapies. Frontiers in Bioscience. 2000;5:E1-E15.

[27] Kessopoulou E, Powers HJ, Sharma KK, et al. A double-blind randomized placebo cross-over controlled trial using the an- tioxidant vitamin $\mathrm{E}$ to treat reactive oxygen species associated male infertility. Fertility and Sterility. 1995;64(4):825-831.

[28] Ford WC, Whittington K. Antioxidant treatment for male subfertility a promise that remains unfulfilled. Human Reproduction. 1998;13(6):1416-1419.

[29] Tarin JJ, Brines J, Cano A. Antioxidants may protect against infertility. Human Reproduction. 1998;13(6):1415-1416.

[30] Greenstein A, Schreiber L, Matzkin H. The effect of methylene blue on histological damage after spermatic cord torsion in a rat model. BJU International. 2001;88(1):90-92. 


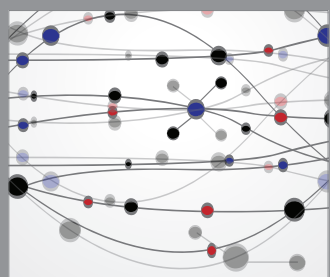

The Scientific World Journal
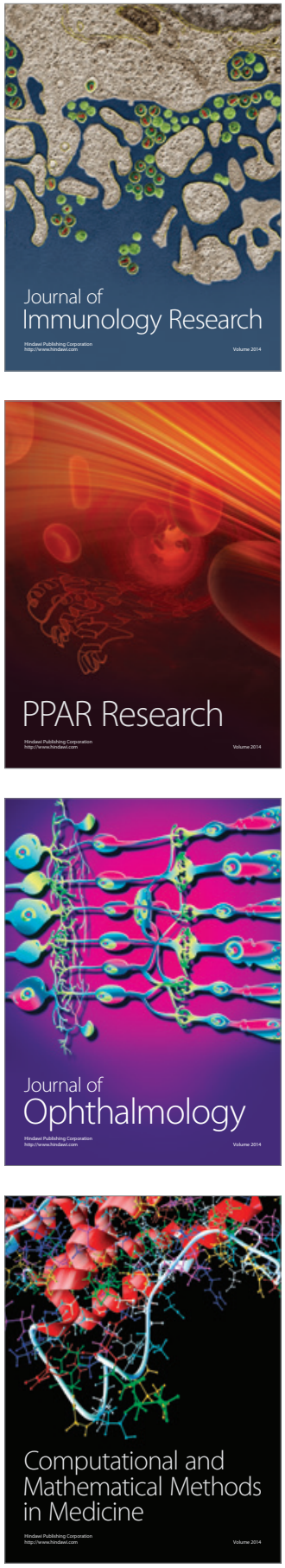

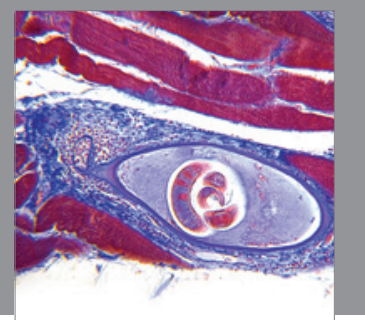

Gastroenterology

Research and Practice
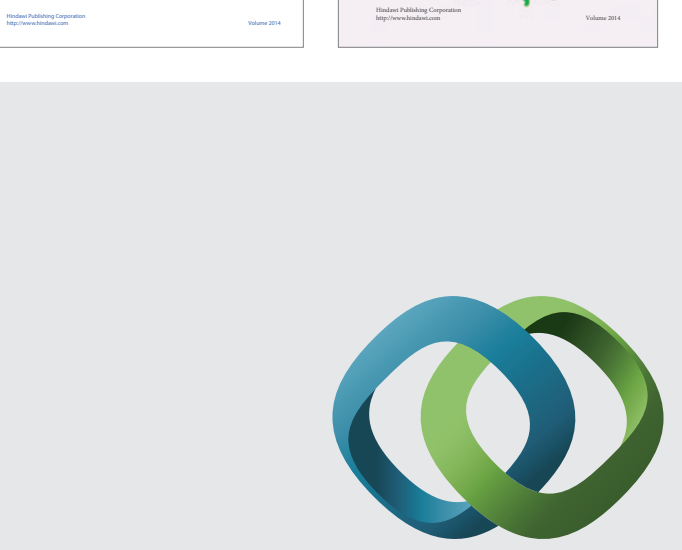

\section{Hindawi}

Submit your manuscripts at

http://www.hindawi.com
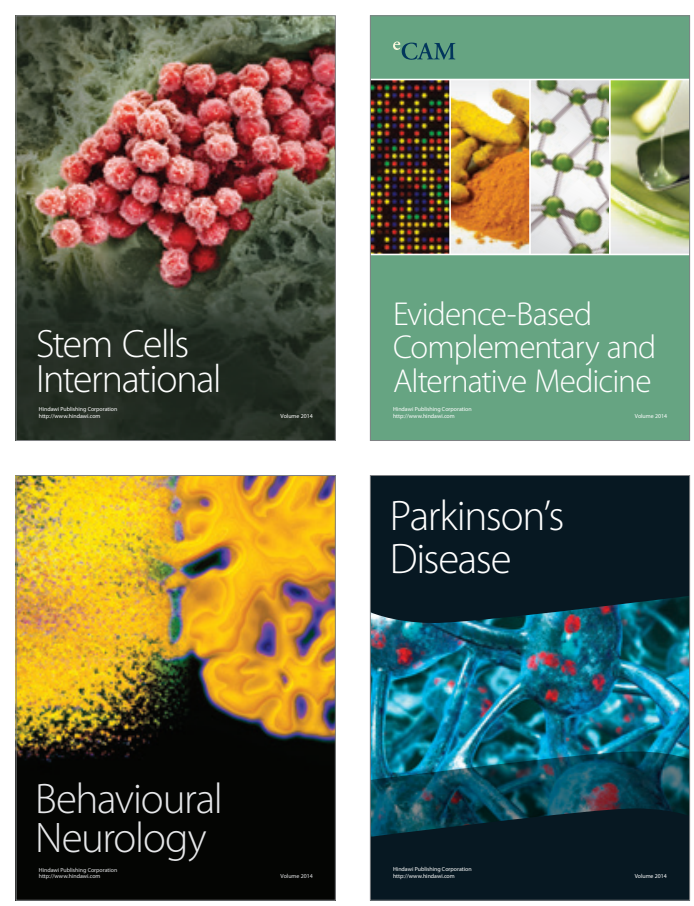

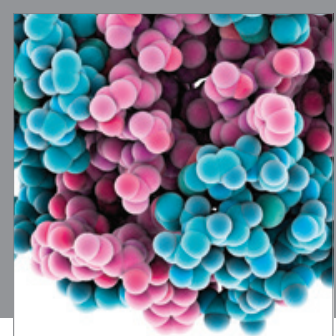

Journal of
Diabetes Research

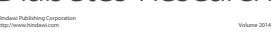

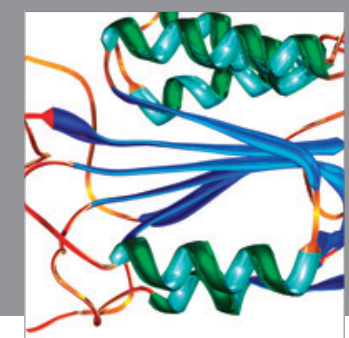

Disease Markers
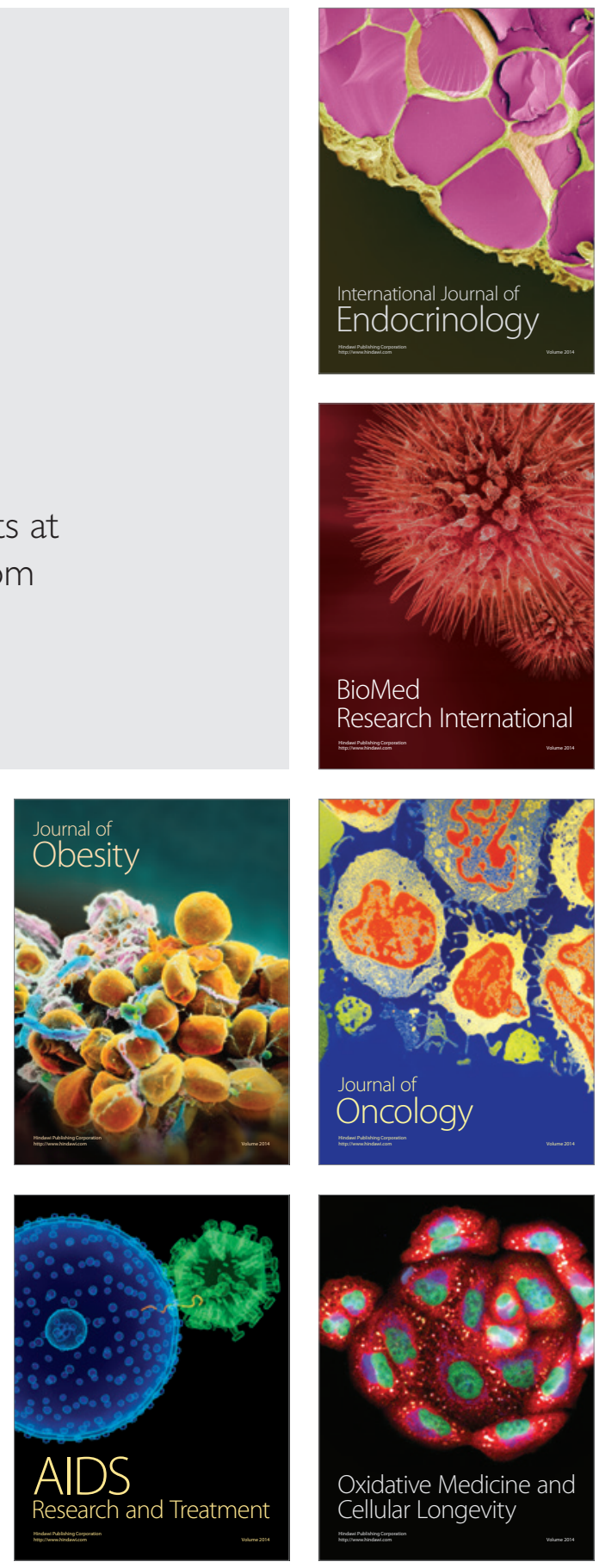